\title{
Requirement of Bccip for the Regeneration of Intestinal Progenitors
}

\author{
Huimei Lu, ${ }^{* \dagger}$ Caiyong Ye, ${ }^{* \dagger}$ Jingmei Liu, ${ }^{* \dagger}$ Arnold B. Rabson, ${ }^{\ddagger \S \uparrow}$ Michael Verzi,, Subhajyoti De, ${ }^{*}$ and Zhiyuan Shen ${ }^{* \dagger}$
}

From the Rutgers Cancer Institute of New Jersey,* New Brunswick; the Departments of Radiation Oncology Pharmacology, Pathology and Laboratory Medicine, ${ }^{\ddagger}$ and Pediatrics, ${ }^{\S}$ and The Child Health Institute of New Jersey, ${ }^{\natural}$ Rutgers Robert Wood Johnson Medical School, New Brunswick; and the Department of Genetics," Human Genetics Institute of New Jersey, Rutgers, The State University of New Jersey, Piscataway, New Jersey

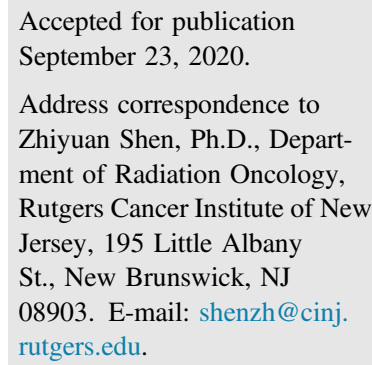

Address correspondence to Zhiyuan Shen, Ph.D., Department of Radiation Oncology, Rutgers Cancer Institute of New Jersey, 195 Little Albany St., New Brunswick, NJ 08903. E-mail: shenzh@cinj. rutgers.edu.

\begin{abstract}
BCCIP was originally identified as a BRCA2 and CDKN1A/p21 interaction protein. Although a partial loss of $B C C I P$ function is sufficient to trigger genomic instability and tumorigenesis, complete deletion of $B C C I P$ is lethal to cells. Using Rosa26-CreERT2 mouse models, we found that induced Bccip deletion in adult mice caused an acute intestinal epithelial denudation that cannot be relieved by co-deletion of Trp53. The critical role of Bccip in intestine epithelial renewal was verified with a Villin-CreERT2 mouse model. The epithelium degeneration was associated with a rapid loss of the proliferative capability of the crypt progenitor cells in vivo, lack of crypt base columnar stem cell markers, and a failure of in vitro crypt organoid growth. RNA-Seq analysis of freshly isolated intestinal crypt cells showed that Bccip deletion caused an overwhelming down-regulation of genes involved in mitotic cell division but an upregulation of genes involved in apoptosis and stress response to microbiomes. Our data not only indicate that intestinal epithelium is the most sensitive tissue to whole-body deletion of Bccip but also point to Bccip as a novel and critical factor for the proliferation of the intestinal progenitors. These findings have significant implications for understanding why a hypomorphic loss of BCCIP functions is more relevant to tumorigenesis. (Am J Pathol 2021, 191: 66-78; https://doi.org/10.1016/ j.ajpath.2020.09.009)
\end{abstract}

The small intestinal epithelium is one of the most proliferative tissues in adult mammals, and is a critical gut barrier, vital for survival. To ensure the integrity of this barrier, a rapid renewal of the functional villus epithelium by crypt stem cells occurs every 3 to 5 days. ${ }^{1}$ This epithelial turnover is ensured by the proper function of stem cells and progenitors, and a tightly regulated homeostasis among cell proliferation, migration, differentiation, and cell death. ${ }^{2,3}$ The intestinal stem cells, located in the crypts, give rise to all other intestinal lineages while maintaining their own population size. ${ }^{4-6}$ Due to the highly proliferative nature of the intestinal crypts, efficient and errorless DNA replication, transcription and RNA processing, and protein synthesis are critical to maintain epithelial integrity.

BCCIP was initially identified as a BRCA2 and p21 (CDKN1A) interacting protein and is evolutionarily conserved from yeasts to mammals. ${ }^{7,8}$ A partial BCCIP knockdown is sufficient to impair DNA damage repair, cell cycle regulation, mitotic spindle dynamics, and genomic stability. ${ }^{9-17}$ Mouse
Bccip is essential for embryonic development. ${ }^{12,18}$ A partial and transient Bccip down-regulation is not only sufficient but also necessary for tumorigenesis in mice. ${ }^{18,19}$ BCCIP downregulation is associated with a poor outcome of laryngeal cancer. ${ }^{20}$ In the current study, we identified a role of Bccip in intestinal renewal using two inducible Bccip knockout models in adult mice. We found that an induced Bccip homozygous deletion caused a rapid denudation of the intestinal epithelium due to crypt collapse and loss of crypt proliferation markers. Using in vitro organoid cultures, the essential role of Bccip in the viability and proliferation of the intestinal progenitors was confirmed. Our data suggest that BCCIP is a critical factor in

Supported by NIH grants R01CA156706 (Z.S.), R01CA195612 (Z.S.), and R01GM129066 (S.D.); a Robert Wood Johnson Foundation award; and Histopathology \& Imaging and Genome Editing Shared Resources of The Rutgers Cancer Institute of New Jersey (supported by NIH grant P30CA072720).

Disclosures: None declared. 
maintaining the intestinal progenitor population and that it plays an important role in intestinal epithelium development.

\section{Materials and Methods}

\section{Mouse Strains}

The animal work presented in this study was approved by the Institutional Animal Care and Use Committee at Rutgers Robert Johnson Medical School. We adhered to and followed all institutional guidelines regarding animal welfare issues. Rosa-CreERT2, Villin-CreERT2, and floxed Trp53 mouse strains have been described in previous reports. ${ }^{5,12,19,21}$ A new mouse strain, designated Bccip ${ }^{f / w t}$, with floxed exon-5 of the $B c c i p$ gene, was generated from embryonic stem cell clones as described elsewhere. ${ }^{18}$ The $B c c i p^{f / w t}$ mice were crossed with each other to generate $B c c i p^{f f f}$ mice, which were then crossed with Rosa-CreERT2, Villin-CreERT2, and floxed Trp53 mice $\left(\operatorname{Trp} 53^{\text {fff }}\right)$ to generate the mouse strains used in this study.

\section{Tamoxifen Treatment}

To induce a translocation of the CreERT2 from cytoplasm to the nucleus, and then trigger LoxP recombination, tamoxifen (MilliporeSigma, Burlington, MA; T5648) was used to treat the mice. Tamoxifen was dissolved at a concentration of $25 \mathrm{mg} / \mathrm{mL}$ in a mixture of $98 \%$ corn oil (Santa Cruz Biotechnology, Dallas, TX; sc-214761A) and 2\% ethanol. A total of $160 \mu \mathrm{L}$ per $25 \mathrm{~g}$ of body weight was injected intraperitoneally into 6- to 8-week-old mice once per day for 3 to 5 days as described later (Results). Corn oil was used as the vehicle control. Mice were genotyped before the pathologic characterization. Pathologic analyses on animals with known genotypes with specified treatment were performed with at least three individual mice. Whenever possible, sex-matched littermates were equally divided into the tamoxifen or oil injection groups.

\section{Antibodies}

The rabbit anti-BCCIP S1472-2 antibodies custom-made by using recombinant BCCIP protein as the antigens have been previously characterized. ${ }^{11,12,19,22}$ Commercial antibodies used were: $\gamma \mathrm{H} 2 \mathrm{AX}$ (Cell Signaling Technology, Danvers, MA; 1:200), Ki-67 (Abcam, Cambridge, MA; 1:300), bromodeoxyuridine (BrdU) (MilliporeSigma; 1:200), p53 (sc1801, Santa Cruz Biotechnology, Dallas, TX; 1:100), and phosphorylated H3 (S10, Cell Signaling Technology, Danvers, MA; 1:100).

\section{Histologic Analysis, Immunohistochemistry, and Terminal Deoxynucleotidyl Transferase-Mediated dUTP Nick-End Labeling Assay}

Tissues were isolated from at least three independent mice in each group, rinsed with phosphate-buffered saline (PBS), fixed in $10 \%$ formalin overnight at $4^{\circ} \mathrm{C}$, and then transferred to $70 \%$ ethanol. The fixed tissues were used to make paraffin blocks by the Histopathology Service of Rutgers Cancer Institute of New Jersey (CINJ). Unless specified by a figure legend, $5-\mu \mathrm{m}$ jejunum sections of the small intestine were cut and used for hematoxylin and eosin and immunohistochemical (IHC) staining. Antibodies listed in Materials and Methods were used for IHC staining according to a previously developed protocol. ${ }^{12,22}$ The DeadEnd Fluorometric TUNEL system (Promega, Madison, WI) was used to detect apoptotic cells. For morphologic quantification, the number of positive cells in 10 to 20 intestinal crypts of each tissue section of each mouse was counted.

\section{Isolation of Intestinal Crypts and Organoid Culture}

Primary organoid cultures were established from jejunum and ileum of $\mathrm{Bccip}^{\text {fff }}$;Rosa-CreERT2 mice. Intestines were immersed into ice-cold PBS without $\mathrm{Ca}^{2+}$ and $\mathrm{Mg}^{2+}$, opened longitudinally, washed in PBS to get rid of lumenal contents, cut into 2- to 3-mm pieces, and washed $3 \times$ with ice-cold PBS until no apparent lumenal contents remained. To neutralize extracellular calcium and magnesium, the intestinal pieces were incubated in $10 \mathrm{~mL}$ of ice-cold crypt isolation buffer $\left(1 \times\right.$ PBS without $\mathrm{Ca}^{2+}$ and $\mathrm{Mg}^{2+}$ containing $2.5 \mathrm{mmol} / \mathrm{L}$ EDTA) at $4^{\circ} \mathrm{C}$ for 5 minutes with shaking at $350 \times g$. They were then transferred into $30 \mathrm{~mL}$ of ice-cold crypt isolation buffer and incubated for another 30 to 40 minutes with shaking at $4^{\circ} \mathrm{C}$.

After discarding the supernatant, $10 \mathrm{~mL}$ of PBS with $0.1 \%$ bovine serum albumin was added, and the suspension was pipetted up-and-down three times. The supernatant was collected and passed through a 70- $\mu \mathrm{m}$ cell strainer and collected as fraction I. These pipetting-and-filtering steps were repeated three more times, to collect fractions II, III, and IV, respectively. Fractions I to IV were centrifuged separately at 50 to $200 \times g$ for 5 minutes at $4^{\circ} \mathrm{C}$; the supernatant was discarded, and the pellets were washed twice with $10 \mathrm{~mL}$ PBS containing $0.1 \%$ bovine serum albumin and collected as the intestinal crypts. After resuspending the crypts with $10 \mathrm{~mL}$ of precultured Dulbecco's Modified Eagle Medium/Nutrient Mixture F-12 with 2 mmol/L GlutaMAX (Thermo Fisher Scientific, Waltham, MA), 10 $\mathrm{mmol} / \mathrm{L}$ HEPES, and $1 \times$ penicillin/streptomycin, $1 \mathrm{~mL}$ of the suspension was transferred to a $30-\mathrm{mm}$ dish and observed microscopically to verify purity. Generally, fractions III and IV yielded better purity. The numbers of crypt per millilier were calculated by microscopically counting 10 $\mu \mathrm{L}$ of crypt suspension. Approximately 3000 crypts were aliquoted and centrifuged at $200 \times g$ for 5 minutes at $4{ }^{\circ} \mathrm{C}$, resuspended in $150 \mu \mathrm{L}$ of organoid culture medium (containing $2 \mathrm{mmol} / \mathrm{L}$ GlutaMAX, $10 \mathrm{mmol} / \mathrm{L}$ HEPES (Thermo Fisher Scientific) $1 \times$ penicillin/streptomycin (Sigma, St. Louis, MO; $1 \times$ N-2 supplement (Thermo Fisher Scientific) $1 \times$ B27 supplement (Thermo Fisher Scientific), $1 \mathrm{mmol} / \mathrm{L}$ 
$\mathrm{N}$-acetylcysteine (Sigma) $50 \mathrm{ng} / \mathrm{mL}$ epidermal growth factor (PeproTech, Rocky Hill, NJ), 100 ng/mL Noggin (PeproTech) and $1 \mu \mathrm{g} / \mathrm{mL}$ R-spondin (R\&D systems, Minneapolis, $\mathrm{MN}$ ), and mixed with $150 \mu \mathrm{L}$ Matrigel (Corning, Edison, $\mathrm{NJ}$ ). A total of $30 \mu \mathrm{L}$ of the mixture was transferred to wells of prewarmed chamber slides (for staining) and $50 \mu \mathrm{L}$ was transferred into wells of the 24-well plates (for time-lapse imaging), and incubated for 10 minutes to solidify the Matrigel. After that, 500 to $600 \mu \mathrm{L}$ of organoid culture medium was added to each well of the 24-well plates for long-term culture.

Between 24 and 36 hours after seeding of the organoids, oil-treated $\mathrm{Bccip}^{\mathrm{fff}} ;$ Rosa-CreERT2 $^{+}$as a control, $0.5 \mu \mathrm{mol} / \mathrm{L}$ final concentration of 4-hydroxytamoxifen (4OHT), dissolved in ethanol at $5 \mathrm{mmol} / \mathrm{L}$ as the stock, was added to Bccip $^{\text {fff }}$;Rosa-CreERT2 organoid culture to induce Bccip deletion and also to $B c c i p^{w t / w t} ;$ Rosa-Cre ERT2 organoid culture as additional control. To monitor organoid growth, the 24-well plates were incubated in the IncuCyte Zoom system (Essen BioScience, Ann Arbor, MI). Time-lapse images were taken every 2 hours for 5 days. To measure the proliferative rate of the organoids, the Click-iT plus EdU Alexa Fluor 594 image kit (Molecular Probes, Eugene, OR) was used according to the manufacturer's instructions, except 6 hours of 5-ethynyl-2'-deoxyuridine (EdU) incorporation was used. EdU images were captured by using a confocal microscope.

\section{RNA-Seq and Data Analysis of Intestinal Crypts}

Eight-week-old Bccip ${ }^{\text {fff }} ;$ Rosa-CreERT2 ${ }^{+}$mice were injected with three daily doses of $80 \mathrm{mg} / \mathrm{kg}$ tamoxifen or oil (as a control). A second control group of mice (Bccip ${ }^{w t / w t} ;$ RosaCreERT2 ${ }^{+}$) received the same tamoxifen treatment. Intestinal crypt cells were isolated 2 days after the completion of tamoxifen treatment. Total RNAs were extracted with a GeneJET RNA Purification Kit (Thermo Fisher Scientific, Vilnius, Lithuania). Extracted total RNA samples were sent to GENEWIZ (South Plainfield, NJ) for RNA-Seq library preparation with the HiSeq Strand-Specific mRNA Sample Preparation system (Illumina, San Diego, CA). RNA-Seq libraries were sequenced with a read length of pair-end $150 \mathrm{bp}$ and $>30$ million reads per sample. After the initial quality check of the paired-end RNA-Seq reads using FastQC (http://www.bioinformatics.babraham.ac.uk/ projects/fastqc, last accessed August 25, 2020), the Salmon ${ }^{23}$ method was used to map them to the catalog of known genes in the mouse reference genome $(\mathrm{mm} 10)$ and quantify transcript-level expression by calculating transcripts per kilobase million values. Edge ${ }^{24}$ was subsequently used to calculate the $P$ value of differential expression between pairs of conditions based on read count data from the samples, using a published approach. ${ }^{25}$ The $P$ values were corrected for multiple testing by using the false discovery rate (FDR). ShinyGo (http://bioinformatics. sdstate.edu/go, last accessed August 24, 2020) was used for the gene ontology enrichment analysis.

The mice used in RNA-Seq were grouped as: i) tamoxifentreated Bccip $^{\text {fff }}$;Rosa-CreERT2 ${ }^{+}$(Bccip knockout), five females and five males; ii) oil-treated $\mathrm{Bccip}^{\text {fff }}$;Rosa-CreERT2 ${ }^{+}$ (Control-1), two females and two males; and iii) tamoxifentreated Bccip ${ }^{w t / w t}$;Rosa-CreERT2 ${ }^{+}$(Control-2), two females and two males. Because principal component analysis clustering suggested no difference between Control-1 and Control-2, these mice were then grouped together as a single control for final data presentation.

\section{Statistical Analysis}

Prism Software (GraphPad Software, La Jolla, CA) was used for two-tailed $t$-tests and $\chi^{2}$ tests. Unless the $P$ value is specifically shown, statistical significance was defined as $* P<0.05, * * P<0.01$, and ${ }^{* * *} P<0.001$.

\section{Results}

Induced Homozygous Bccip Deletion in Adult Mice Impairs the Intestinal Epithelial Renewal

In a previous study, we showed that a partial depletion of Bccip by RNA interference was sufficient to cause embryonic lethality. ${ }^{12}$ Recently, we generated a C57BL6N JM8 mouse embryo stem cell clone in which lox $P$ sites were introduced to flank exon-5 of Bccip (floxed allele), resulting in a conditional $B c c i p^{f / w t}$ allele and subsequently a conditional Bccip germline knockout mouse strain. ${ }^{18}$ The Bccip ${ }^{f / w t}$ germline strain was fertile and successfully produced homozygous conditional Bccip mice, designated Bccip ${ }^{f f f}$. However, upon breeding with EIIa-Cre, the conditional Bccip $^{f f f}$ mice were embryonic lethal, ${ }^{18}$ and this prohibited the possibility of establishing a constitutive whole-body knockout mouse strain to study the function of Bccip in adult mice.

To enable investigation of the role of Bccip in postnatal whole-body development, an inducible knockout mouse model was generated using the Rosa-CreERT2 system. The conditional $\mathrm{Bccip}^{\text {fff }}$ mice were crossed with Rosa-CreERT2 mice, resulting in $B c c i p^{f / w t} ;$ Rosa-CreERT2 $2^{+}$mice, which were then crossed with $\mathrm{Bccip}^{f f f}$. This cross produced offspring with the anticipated distribution of genotypes (Supplemental Table S1), suggesting that $B c c i p^{\text {fff }} ;$ Rosa-CreERT2 ${ }^{+}$mice were viable. These mice also have a normal life span. After five daily intraperitoneal injections of tamoxifen in 8to 10-week-old mice, it was surprisingly found that the Bccip $^{\text {fff }} ;$ Rosa-CreERT2 ${ }^{+}$mice experienced diarrhea and rapid weight loss. All Bccip ${ }^{f f f}$;Rosa-CreERT2 ${ }^{+}$mice, except one that failed to undergo the LoxP recombination, died within 4 days (average, $2.7 \pm 0.8$ days) (Table 1). However, the heterozygous mice $\left(B c c i p^{f / w t} ;\right.$ Rosa-CreERT2 $\left.{ }^{+}\right)$and two control groups of mice $\left(\mathrm{Bccip}^{w t / w t} ;\right.$ Rosa-CreERT2 ${ }^{+}$and Bccip $^{f f f} ;$ Rosa-CreERT2 $^{-}$) survived after tamoxifen treatment. 
These data suggest that complete Bccip deletion in adult mice causes lethality. The genotyping strategies to distinguish the wild type, floxed exon 5 , and the deleted exon 5 ( $\Delta$ Exon5) are summarized in Figure 1A. The effectiveness of tamoxifeninduced Bccip deletion in various tissues was verified by PCR genotyping of individual organs (Figure 1B).

Because tamoxifen injections caused weight loss and severe diarrhea, and the $\mathrm{Bccip}^{f f f} ;$ Rosa26-CreERT2 $^{+}$mice died within 4 days, which is the same time frame for the self-renewal of mouse intestinal epithelium from crypts to villi, ${ }^{4}$ we suspected that these mice may have died of acute gastrointestinal failure. Indeed, gross observation of the intestine and mesentery confirmed this prediction (Figure 2A). Furthermore, a series of histologic analyses of the small intestine showed that tamoxifen injections resulted in the denudation of the intestinal epithelium (Figure 2B), and degeneration of the epithelium was observed even if the mice received only three daily injections of tamoxifen (Supplemental Figure S1). No gross or histologic abnormalities were observed in the Bccip $^{\text {wt } / w t} ;$ Rosa-CreERT2 ${ }^{+}$ and Bccip $^{f f f} ;$ Rosa-CreERT2 ${ }^{-}$mice. The effectiveness of BCCIP protein loss in both the villi and crypt cells was verified by using IHC staining (Supplemental Figure S2). At the early time of animal dissection, there were no major histologic abnormalities in the villi despite BCCIP depletion in these regions, but a shortening of villi length could be observed as early as 3 days after tamoxifen treatment (Supplemental Figure S3), likely caused by the lack of supply of the villus cells due to crypt dysfunction.

Previous studies have shown that a $<50 \%$ loss of BCCIP is sufficient to impair DNA repair in cell lines, ${ }^{10,16}$ and purified BCCIP protein can promote conformational change of the RAD51 filament. ${ }^{25} \gamma \mathrm{H} 2 \mathrm{AX}$ formation at various times before the mice were euthanized was therefore monitored. Starting at the third day after three tamoxifen injections, there was a significant increase in $\gamma \mathrm{H} 2 \mathrm{AX}$-positive cells in the crypts (Figure 3, A and C) accompanied by the appearance of apoptotic cells positive for terminal deoxynucleotidyl transferase-mediated dUTP nick-end labeling (Figure 3, B and D). BCCIP protein was effectively reduced in both villi and the crypts (Supplemental Figure S2), but only the crypt cells displayed $\gamma \mathrm{H} 2 \mathrm{AX}$ accumulation and apoptotic cell death (Figure 3). This outcome indicates that Bccip is critical for the viability of proliferating cells but not necessary for terminally differentiated cells. There was a consistent and significant decrease in the proliferation index as reflected by $\mathrm{BrdU}$ incorporation (Figure 4, A and C) and presence of $\mathrm{Ki}$ 67-positive (Figure 4, B and D) cells in the crypts after tamoxifen treatment. The crypts of the large intestine had morphologic changes similar to those of the small intestine, albeit with less severity, including apoptosis (data not shown).

Data from Rosa-CreERT2 mice (Figures 2, 3, and 4) suggested that the intestine was likely the most sensitive tissue upon induced whole-body deletion of Bccip. To address whether Bccip deletion in the intestine alone is sufficient to cause the same adult lethality, Bccip $^{\text {fff }}$ were crossed with Villin-CreERT2 ${ }^{+}$ mice, which express CreERT2 specifically in the villus and crypt epithelial cells of the small and large intestines. Treatment of Bccip $^{\text {fff }}$;Villin-CreERT2 ${ }^{+}$mice with four daily tamoxifen (50 $\mathrm{mg} / \mathrm{kg}$ ) injections was sufficient to cause adult lethality (3.77 \pm 0.8 days) (Table 1$)$. These mice had collapsed intestinal crypts (Supplemental Figure S4A). As expected, the BCCIP protein depletion was confirmed in the intestinal epithelium (Supplemental Figure S4B). Similar to the Rosa-CreERT2 model, these mice had spontaneous activation of $\gamma \mathrm{H} 2 \mathrm{AX}$ (Figure 5A), reduction of mitotic cells (Figure 5B), and an increase in apoptotic cell death in the crypts (Figure 5C). Thus, the Villin-CreERT2 model phenocopied the Rosa26-CreERT2 model and reached the same conclusion that Bccip is essential for the regeneration of the intestinal epithelium and the proliferation of the crypt progenitors. Despite deletion of Bccip in other tissues, the acute phenotype observed in $B c c i p^{\text {fff }} ;$ Rosa-CreERT2 ${ }^{+}$ mice is similar to that in the Bccip ${ }^{\text {fff }}$;Villin-CreERT2 ${ }^{+}$mice. This implies that the intestinal damage was the primary cause of fatality in the mice with the Bccip deletion.

\section{Bccip Deletion Impairs the Proliferation of Stem and Progenitor Cells in the Intestine}

The intestinal crypts are not only the niche of proliferative progenitor and stem cells, but also host quiescent stem cells. The crypts were isolated and real-time PCR was performed

Table 1 Survival after Bccip Deletion Induced by Tamoxifen Injections

\begin{tabular}{|c|c|c|c|c|}
\hline \multirow[b]{2}{*}{ Genotype } & \multicolumn{2}{|l|}{ Tamoxifen } & \multicolumn{2}{|l|}{ Oil } \\
\hline & Injected, $n$ & Survived, $n$ & Injected, $n$ & Survived, $n$ \\
\hline Bccip $^{f / f} ;$ Rosa-CreERT2 ${ }^{+/-}$ & $15(8 \mathrm{M}, 7 \mathrm{~F})$ & $1(1 \mathrm{M})$ & $7(4 \mathrm{M}, 3 \mathrm{~F})$ & $7(4 \mathrm{M}, 3 \mathrm{~F})$ \\
\hline Bccip $^{w t / w t} ;$ Rosa-CreERT $T^{+/-}$ & 5 & 5 & 5 & 5 \\
\hline Bccip ${ }^{f / w t} ;$ Rosa-CreERT $T^{+/-}$ & 40 & 40 & 19 & 19 \\
\hline Bccip $^{f / w t} ;$ Rosa-CreERT ${ }^{\prime-}$ & 15 & 15 & 5 & 5 \\
\hline
\end{tabular}

$F$, female; $M$, male. 
A
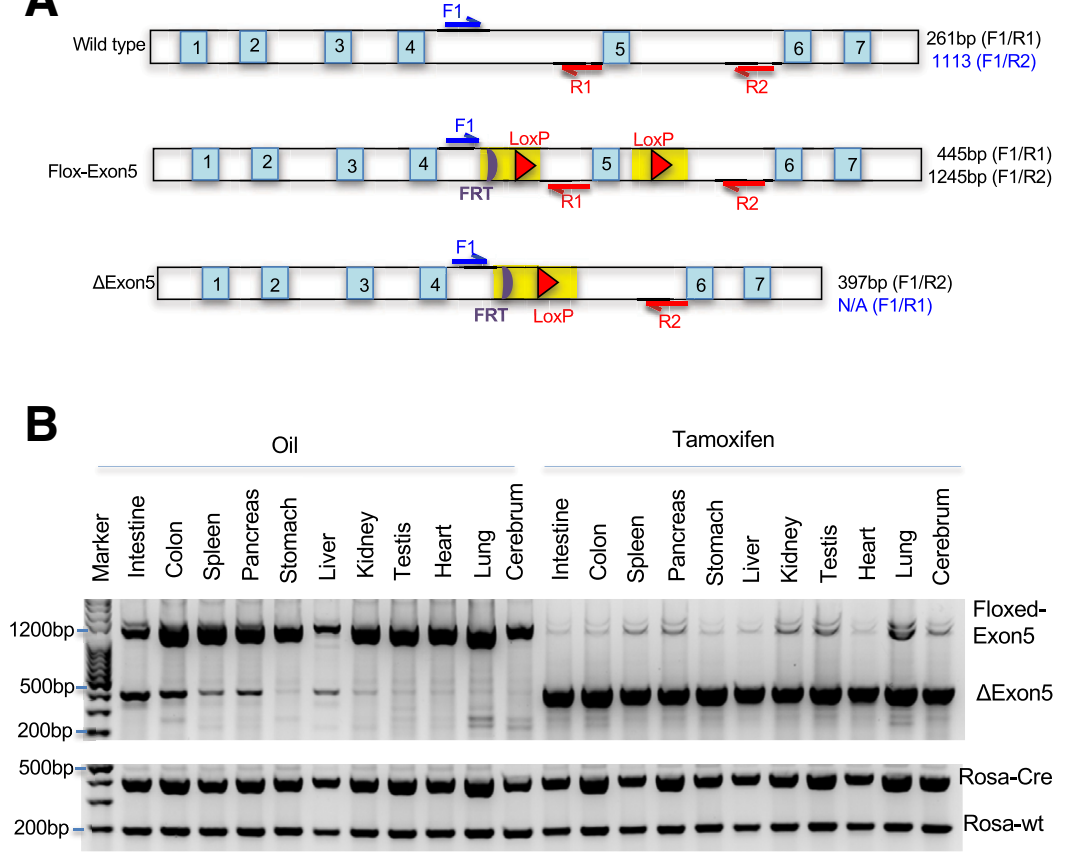

Figure 1 Tamoxifen-induced Bccip deletion. A: Genomic structure of the Bccip alleles and PCR genotyping strategy. Illustrated are the genomic structures of the wild-type Bccip, exon-5 floxed Bccip (Flox-Exon5), and exon-5 deleted Bccip ( $\Delta$ Exon5) alleles. The primer locations and expected PCR product sizes are indicated. Genotyping primers are: F1 (SCF1): 5'-CGGAGTCTTCTGTGTCAGACT-3' (forward); R1 (SCR1): $5^{\prime}$-TTCTTCTCAGAGAATAAGCGG-3' (reverse); R2 (KO-SCG-R1): $5^{\prime}$ GAAGTAGGGGCAGTATTAAGG-3' (reverse). B: Confirmation of tamoxifen-induced Bccip deletions in various tissues. DNA from indicated tissues was isolated and used for PCR genotyping. Shown is a pair of representative littermates that were euthanized 1 day after five daily injections of oil (control) or tamoxifen (Bccip deletion). The PCR products of floxed-Exon5, $\Delta$ Exon5, Rosa-CreERT2, and wild-type Rosa alleles are indicted on the right side of the panels. Genotyping primers for the Bccip alleles are shown in $\mathbf{A}$. The primers for the Rosa26 alleles are: Rosa-Fw: $5^{\prime}$ CTGGCTTCTGAGGACCG-3' (forward); Rosa-Rev: $5^{\prime}$ CCGAAAATCTGTGGGAAGTC- $3^{\prime}$ (reverse). This produces an approximately 200 bp product for wild-type Rose26 and an approximately 340 bp band for the Rosa-CreERT2 allele. Some background LoxP recombination was observed in the oil-treated tissues. to detect the abundance of several proliferative and quiescent stem cell markers. Crypts isolated from tamoxifentreated mice lack expression of the proliferative Lgr5+ crypt base columnar stem cell markers ( $\operatorname{Lgr} 5$, Olfm 4 , and Smoc2), but the levels of Bmil and Hopx (markers for the quiescent +4 stem cells) remain stable (Figure 6A). These data suggest that Bccip deficiency preferentially affects the proliferative progenitors in the crypts.

To further characterize the role of Bccip in intestinal epithelial renewal, intestinal organoids from the Bccip $^{f f f} ;$ Rosa-CreERT2 ${ }^{+/-}$mice were cultured and deletion of Bccip was induced by treating the organoid culture with 4OHT. Both ethanol-treated Bccip ${ }^{f f f} ;$ Rosa-CreERT2 $^{+}$and 4OHT-treated Bccip ${ }^{w t / w t} ;$ Rosa-CreERT2 ${ }^{+}$organoids were used as the control. After labeling and staining the organoid with EdU, multiple organoids were scored and it was found that the $\mathrm{Bccip}^{\text {fff }}$;Rosa-CreERT2 ${ }^{+}$organoids stopped branch formation after 3 days of $4 \mathrm{OHT}$ treatment, and the percentage of organoids with at least two branches continued to increase for the controls (Figure 6B). EdU was efficiently incorporated into the growing buds of the control organoids, but its incorporation into the 4OHT-treated organoids was severely reduced (Figure 6C). A representative set of threedimensional images of the EdU-labeled organoids collected at day 3 are illustrated in Supplemental Video S1 (ethanoltreated $\mathrm{Bccip}^{f f f} ; \mathrm{CreERT2}^{+}$as a control), Supplemental Video S2 (4OHT-treated Bccip ${ }^{f / f}$;CreERT2 ${ }^{+}$), and Supplemental Video S3 (4OHT-treated Bccip ${ }^{w / w}$;CreERT2 ${ }^{+}$as another control). The control organoids continued to grow, but $\mathrm{Bccip}^{f /}$ ${ }_{\text {; }}^{f}$ Rosa-CreERT2 ${ }^{+}$organoids ceased growth at 2 to 3 days after $4 \mathrm{OHT}$ exposure (Figure 6D). These in vitro organoid data confirmed the essential role of Bccip in the viability and proliferation of these intestinal progenitor cells. A representative set of time-lapse images of organoid growth is shown in Supplemental Video S4 (ethanol-treated Bccip ${ }^{f \prime}$ ${ }_{\text {; }} \mathrm{CreERT2}^{+}$as a control), Supplemental Video S5 (4OHTtreated $\mathrm{Bccip}^{\text {fff }}$; $\mathrm{CreERT2}^{+}$), and Supplemental Video S6 (4OHT-treated $\mathrm{Bccip}^{w / w} ; \mathrm{CreERT2}^{+}$as another control).

\section{Trp53 Deletion Does Not Rescue the Lethality Caused by Bccip Deletion}

Spontaneous DNA damage activates p53 and subsequently causes cell death. Cell lethality caused by DNA repair defects can often be relieved by co-deletion of Trp53. p53 Nuclear accumulation was observed in crypts of tamoxifen-treated Bccip $^{\text {fff }} ;$ Rosa-CreERT2 ${ }^{+}$mice at later time points (Supplemental Figure S5). Considering that Bccip deletion caused $\gamma \mathrm{H} 2 \mathrm{AX}$ accumulation and apoptotic cell death (Figure 3), it was investigated whether co-deletion of Trp53 would rescue the lethality of the intestinal stem and progenitor cells. Floxed conditional Trp53 mice $\left(\operatorname{Tr} p 53^{\text {fff }}\right)$ were crossed with conditional Bccip mice, generating $B c c i{ }^{\text {fff }} ; \operatorname{Trp} 53^{\text {fff }} ;$ Rosa$\mathrm{CreERT2}{ }^{+/-}$mice. Treatment of these mice with the same dose of tamoxifen resulted in death within 4 days $(3.3 \pm 0.5$ days $)$ (Table 1, which was not significantly different from that observed in the Bccip ${ }^{\text {fff }} ;$ Rosa-CreERT2 ${ }^{+/-}$mice. Thus, codeletion of $\operatorname{Trp} 53$ did not rescue the adult lethality caused by Bccip deletion. These data indicate that the cause of lethality among Bccip null mice cannot be fully explained by an accumulation of spontaneous DNA damage in these cells, and is 
A

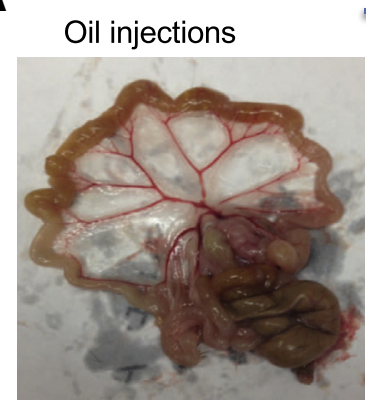

B

1 day after 5 daily oil injections (control)
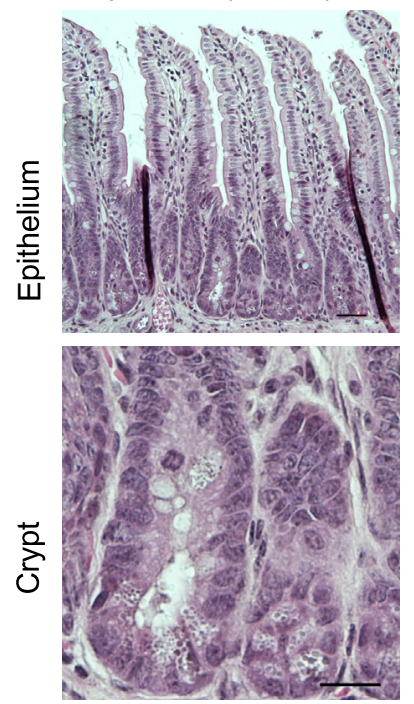

Days after 5 daily tamoxifen injections
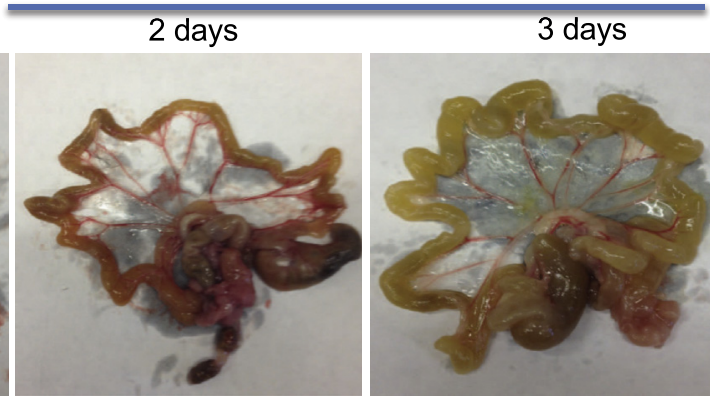

1 day after 5 daily tamoxifen injections
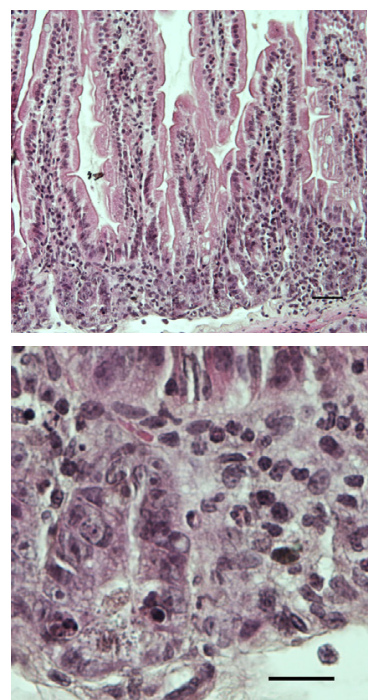

3 days after 5 daily tamoxifen injections
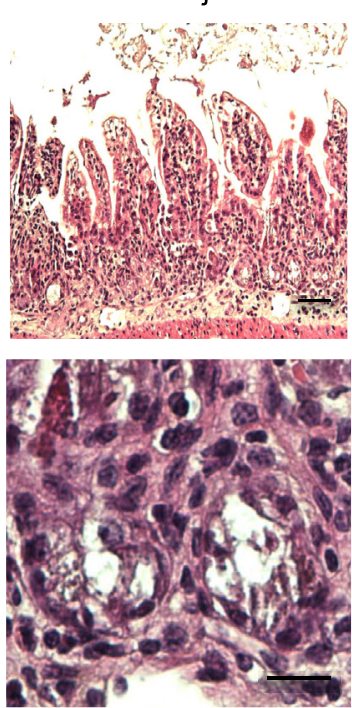

Figure 2 Intestinal degeneration caused by induced Bccip knockout in adult mice. Adult mice were injected with tamoxifen, and gross anatomic, histopathologic, and immunohistochemical analyses of the intestinal tissues were performed. The number of tamoxifen or oil injections and the time of tissue analyses are indicated on the top of each panel. A: Representative gross anatomy of intestine at the indicated time after oil (control) or tamoxifen injections. B: Representative hematoxylin and eosin histology of jejunum sections of the intestinal tissues at the indicated time after oil (control) and tamoxifen injections. Top row: Both crypt and villi regions; bottom row: crypt region. Scale bars: $80 \mu \mathrm{m}$ (B, top row); $20 \mu \mathrm{m}$ (B, bottom row). Original magnification: $\times 10$ (B, top row); $\times 40$ (B, bottom row). distinct from the Notchless deletion-induced intestinal collapse that can be rescued by co-deletion of $\operatorname{Trp} 53 .^{26}$

\section{Recombinant Mouse Wnt3a Protein Fails to Rescue or Delay the Growth Arrest Caused by Bccip Deletion}

One of the major pathways involved in the establishment of tissue architecture during development is the canonical Wnt/ $\beta$-catenin signaling pathway. ${ }^{27}$ It persists as a key regulator of homeostasis in adult self-renewing tissues. The intestinal epithelium represents the best-understood example of the closely linked roles of Wnt signaling in homeostatic selfrenewal. ${ }^{28}$ Block of $W n t / \beta$-catenin signaling results in rapid loss of transient-amplifying cells and crypt structures. ${ }^{29}$ Wnt3a protein is a ligand for members of the Frizzled family of transmembrane receptors. ${ }^{30}$ To explore whether recombinant mouse Wnt3a protein can rescue Bccip deletion-induced proliferating cell growth defects, the organoids were treated with $0.5 \mu \mathrm{mol} / \mathrm{L} 4 \mathrm{OHT}$ with or without $100 \mathrm{ng} / \mathrm{mL} \mathrm{Wnt} 3 \mathrm{a}$, and vehicle with or without
Wnt3a, respectively. Organoid growth was monitored in the IncuCyte Zoom system and imaged every 2 hours for 5 days. The Wnt3a treatment failed to rescue the growth defect of the 4OHT-treated organoids, which are represented in the following set of time-lapse videos of cultured Bccip ${ }^{\text {f/ }}$ ${ }_{\text {; }}$ CreERT2 $^{+}$organoids: ethanol-treated but not Wnt3atreated (Supplemental Video S7); ethanol- and Wnt3atreated (Supplemental Video S8); 4OHT-treated but not Wnt3a-treated (Supplemental Video S9); and 4OHT- and Wnt3a-treated (Supplemental Video S10).

These data indicate that Wnt3a cannot rescue growth arrest caused by Bccip deletion.

\section{Bccip Deletion Down-Regulates Genes Involved in Mitotic Cell Division}

To explore the mechanism by which Bccip deletion hinders the intestinal renewal, RNA-Seq analyses were performed with freshly isolated intestinal crypts at 2 days after three daily injections of tamoxifen. This time point is considered 
A

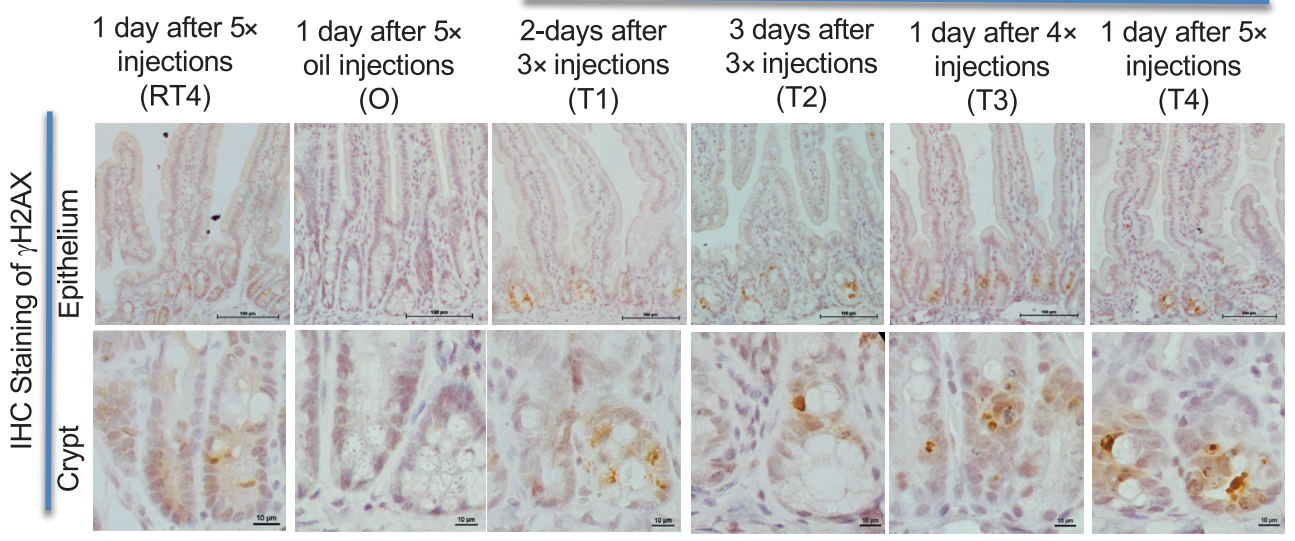

B
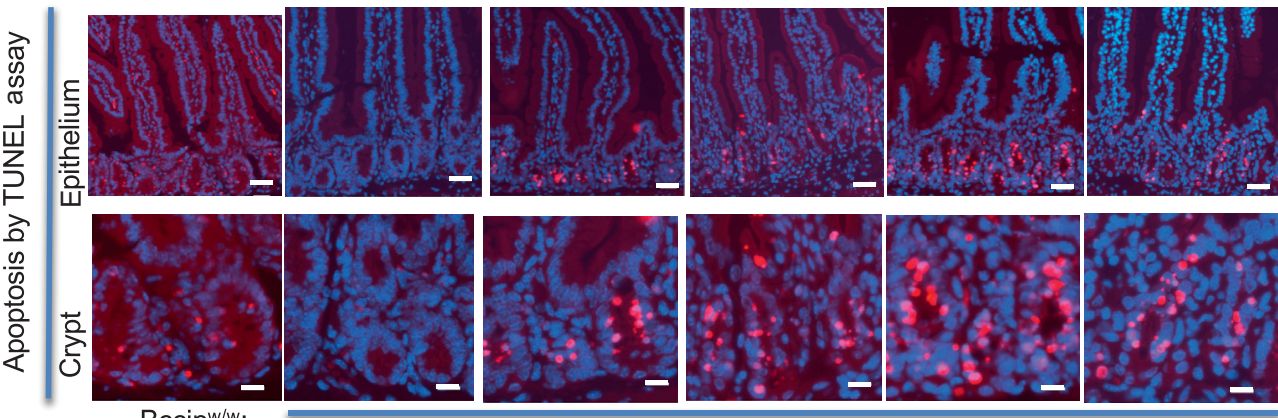

RosaCreERT2
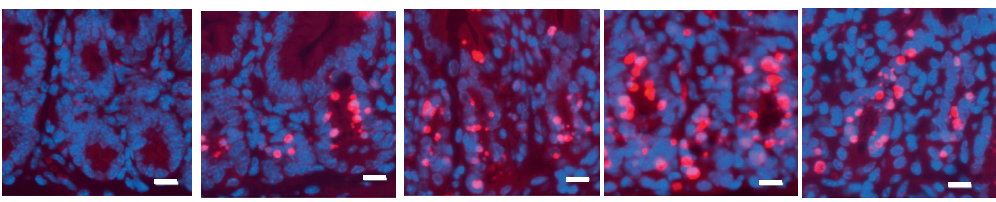

Bccip fff; RosaCreERT2+ $^{+}$

C

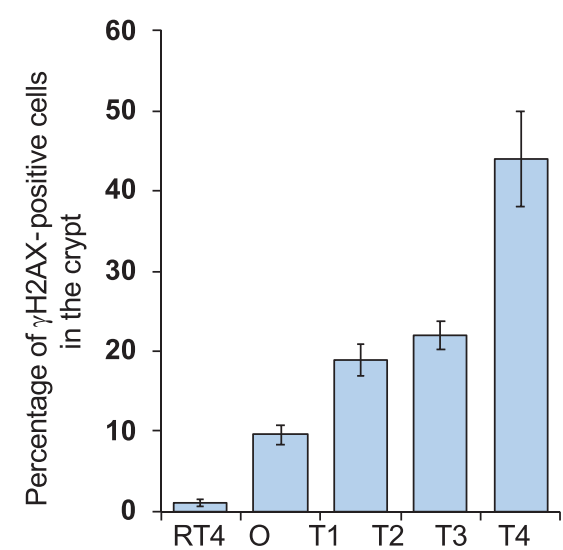

D

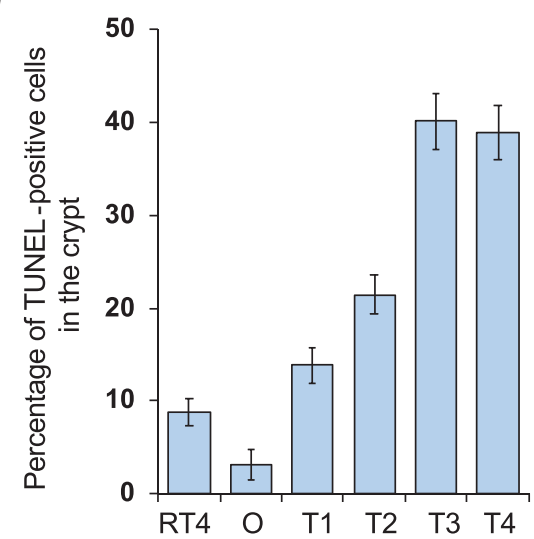

Figure 3 Increased spontaneous DNA damage and apoptosis in Bccip knockout intestine. Shown are representative $\gamma \mathrm{H} 2 \mathrm{AX}(\mathbf{A})$ and terminal deoxynucleotidyl transferase-mediated dUTP nick-end labeling (TUNEL) (B) staining of jejunum sections of the intestinal epithelium. In each set of figures, the top rows show both crypt and villi; the bottom rows show crypt region. $\mathbf{C}$ and $\mathbf{D}$ : Bar graphs showing the average percentage and SEMs of crypt cells that were positive for $\gamma \mathrm{H} 2 \mathrm{AX}$ and TUNEL at the same time points as shown in A and B. 0, oil-treated Bccip ${ }^{f / f} ;$; Rosa-CreERT2 ${ }^{+}$as another control; RT4, tamoxifen-injected $B c c i p^{w t / w t} ;$ Rosa-CreERT2 ${ }^{+}$control mice; T1-T4, tamoxifen-treated Bccip ${ }^{f / f} ;$ Rosa-CreERT2 ${ }^{+}$mice $(\mathrm{T} 1$, two days after three daily tamoxifen injections; $\mathrm{T} 2$, three days after three daily tamoxifen injections; T3, one day after four daily tamoxifen injections; T4, one day after five daily tamoxifen injections). Scale bars: $\times 10$ $100 \mu \mathrm{m}$ (A, top row); $10 \mu \mathrm{m}$ (A, bottom row); $50 \mu \mathrm{m}$ (B). Original magnification: $\times 10$ (A and B, top rows); $\times 40$ (A and $\mathbf{B}$, bottom rows).

as the early phase of crypt collapse (Figures 3 and 4). Intestinal crypts were isolated from 10 tamoxifen-treated Bccip $^{f f f} ;$ Rosa-CreERT2 ${ }^{+}$(Bccip knockout) mice. Four oiltreated littermate $B c c i p^{\text {fff }} ;$ Rosa-CreERT2 $2^{+}$and four tamoxifen-treated $B c c i p^{w t / w t} ;$ Rosa-CreERT2 ${ }^{+}$mice were used as the control. The two controls were grouped together for the final data presentation because principal component analysis clustering suggested no difference between them.
After filtering the genes with an false discovery rate 0.01 , and at least twofold changes between Bccip deletion and the controls, a total of 301 down-regulated genes and 262 upregulated genes were identified (Figure 7A). These differentially expressed genes are listed in Supplemental Table S2; they all had a $P$ value $<0.0007$ and thus are highly significantly altered upon Bccip deletion. Gene Ontology analysis revealed that the up-regulated genes were highly 
A

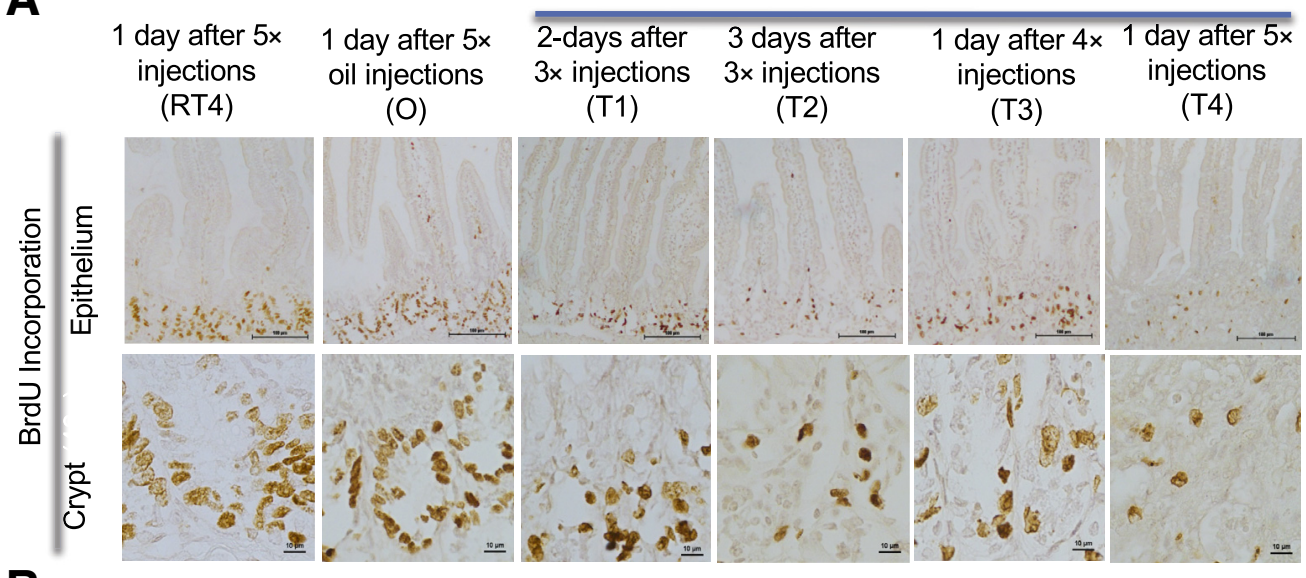

B

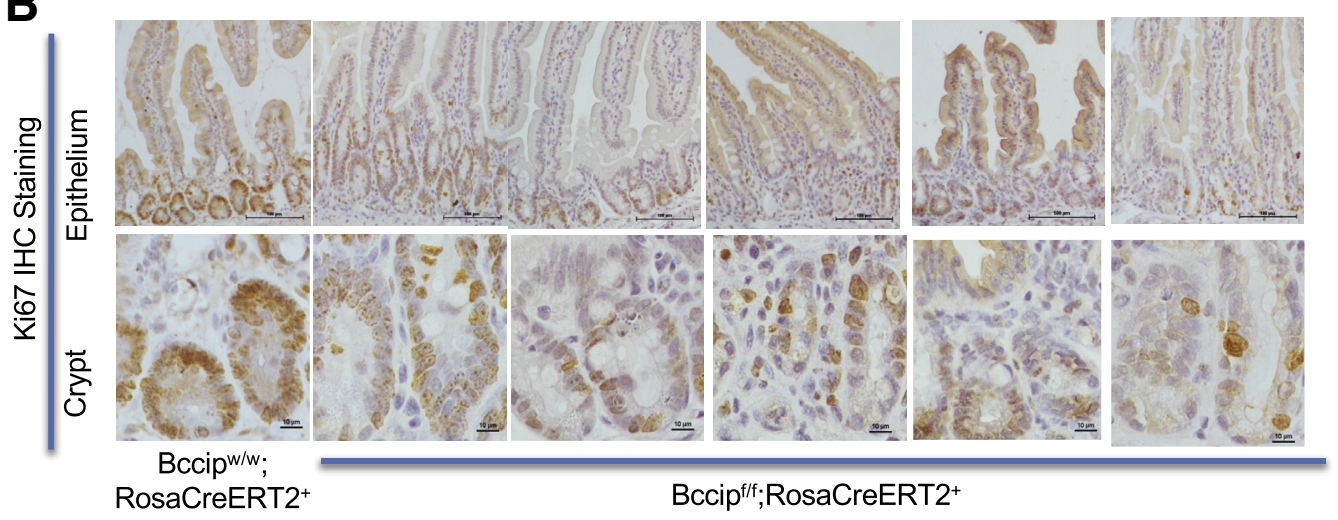

C

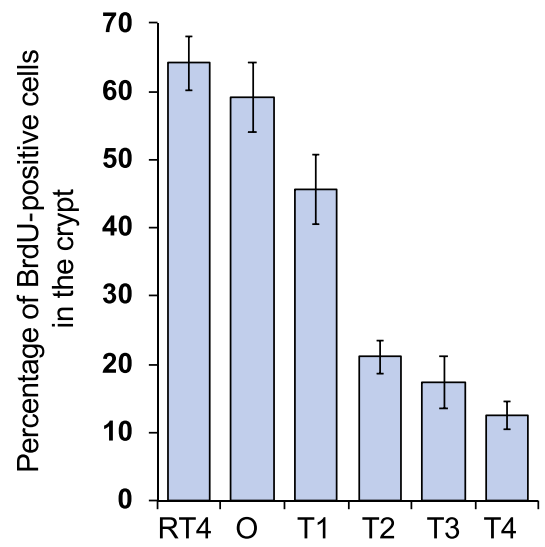

Days after tamoxifen injections

injections injections injections

D

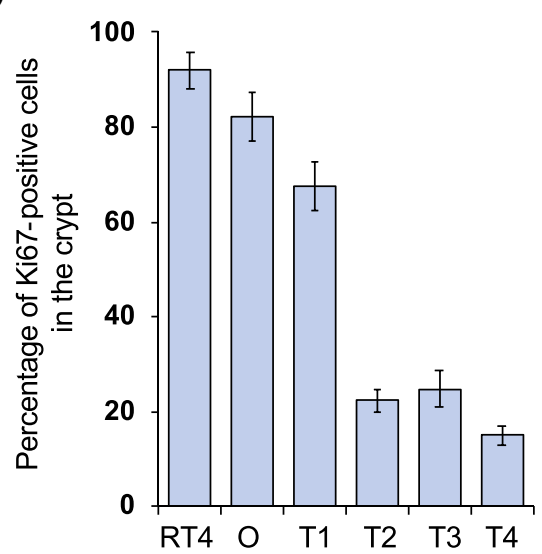

Figure 4 Impaired cell proliferation in the crypts. One hour before euthanasia, mice were injected with bromodeoxyuridine (BrdU) to label proliferative cells. A: Incorporated BrdU was stained in brown using anti-BrdU antibody. B: The Ki-67-positive cells were identified by brown staining with immunohistochemistry. In the representative image panels, the top panel shows both crypt and villi, and the bottom panel shows crypt. $\mathbf{C}$ and $\mathbf{D}$ : Bar graphs showing the average percentage and SEMs of crypt cells that were positive for BrdU and Ki-67 at the same time points as shown in $\mathbf{A}$ and $\mathbf{B}$. 0, oil-treated Bccip f $^{f / f}$; RosaCreERT2 ${ }^{+}$as another control; RT4, tamoxifen-injected Bccip ${ }^{\text {wt } / w t}$; Rosa-CreERT2 ${ }^{+}$control mice; T1-T4, tamoxifen-treated Bccip ${ }^{f / f} ;$ Rosa-CreERT2 $^{+}$mice $\left(\mathrm{T}_{1}\right.$, two days after three daily tamoxifen injections; T2, three days after three daily tamoxifen injections; T3, one day after four daily tamoxifen injections; and T4, one day after five daily tamoxifen injections). Scale bars: $100 \mu \mathrm{m}$ (A and $\mathbf{B}$, top rows); $10 \mu \mathrm{m}$ (A and $\mathbf{B}$, bottom rows). Original magnification: $\times 10$ (A and $\mathbf{B}$, top panels); $\times 40$ (A and B, bottom panels).

clustered in pathways involved in the cell cycle, especially in mitosis, including chromosome segregation and spindle organization (Figure 7, B and C). Conversely, the upregulated genes were highly clustered in the processes of defense response to other organisms and stress, and apoptotic cell death (Figure 7, D and E). These data suggest that Bccip deletion likely initiated a proliferation failure by severing mitosis and caused apoptotic cell death. Another intriguing observation is the up-regulation of genes in response to bacterium, defense to virus, and other 
A

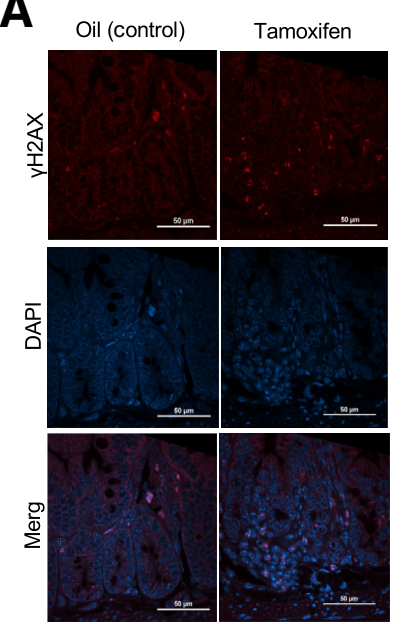

B

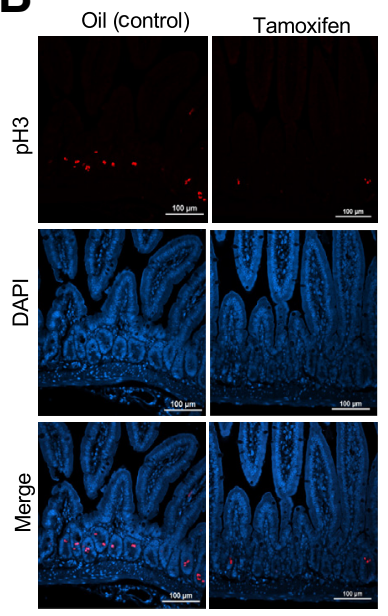

\section{5 days after 4 oil injections}
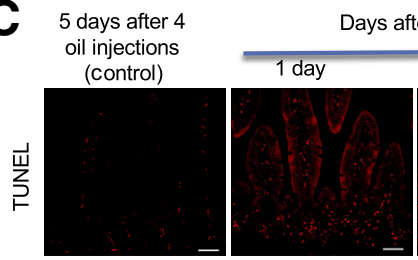

Days after tamoxifen injections
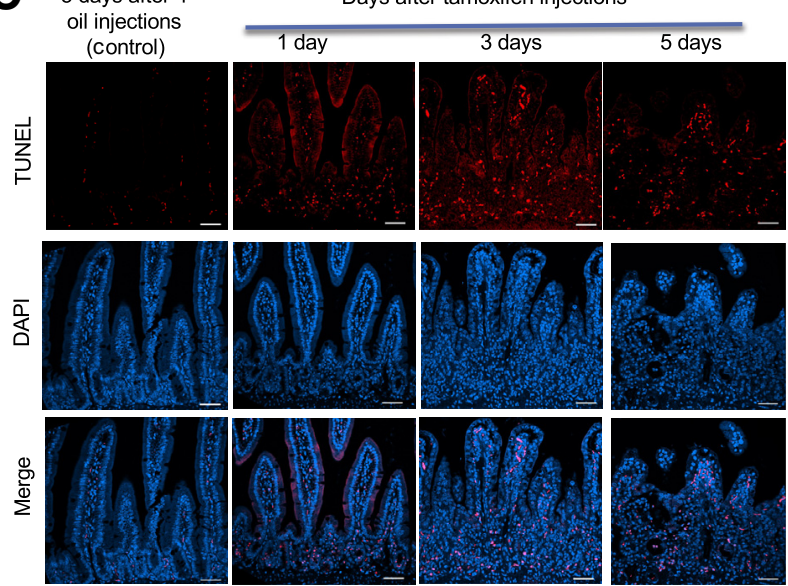

Figure 5 Characterization of intestinal defects in Bccip ${ }^{f / f}$; Villin-CreERT2 mice after tamoxifen treatment. A: Level of $\gamma \mathrm{H} 2 \mathrm{AX}$ in the intestinal crypts of the Bccip $p^{f / f}$;Villin-CreERT2 mice. Shown is representative immunofluorescent staining of intestine 1 day after four daily tamoxifen injections. Left column: oil injection as control; right column: tamoxifen injection; top row: $\gamma \mathrm{H} 2 \mathrm{AX}$ staining in red; middle row: DAPI; bottom row: merged image. B: Mitotic index in the intestinal crypts of the Bccip ${ }^{f / f}$; Villin-CreERT2 mice. Shown is representative immunofluorescent phosphorylated $\mathrm{H} 3(\mathrm{pH} 3)$ staining of the intestinal tissue 1 day after four daily tamoxifen injections. Left column: oil injections as control; right column: tamoxifen injections; top row: $\mathrm{pH} 3$ staining in red; middle row: DAPI; bottom row: merged image. C: Apoptosis in the intestinal crypts of the Bccip ${ }^{\mathrm{f} / f}$; Villin-CreERT2 mice. Top row: apoptotic cells stained in red by terminal deoxynucleotidyl transferase-mediated dUTP nick-end labeling (TUNEL) assay; middle row: DAPI; bottom row: merged images. The treatment and time of tissue collection are indicated on the top of the panel. Scale bars: $50 \mu \mathrm{m}$ (A and C); $100 \mu \mathrm{m}$ (B).

organisms. This may reflect a response of the crypt cells to microbiome infiltration due to the functional loss of intestinal epithelium barrier.

\section{Discussion}

In this study, it was found that induced homozygous Bccip whole-body deletion in adult mice caused a severe intestinal epithelial denudation that cannot be relieved by co-deletion of Trp53. The epithelium degeneration was associated with a rapid loss of the proliferative capability of the crypt progenitor cells in vivo and a lack of crypt base columnar stem cell markers. At the cellular and molecular level, the pathologic changes caused by Bccip deletion were associated with a lack of S-phase cells and mitotic cells (Figures 4 and $5 \mathrm{~B}$ ), a robust induction of spontaneous DNA damage (Figures $3 \mathrm{~A}$ and $5 \mathrm{~A}$ ), and a reduction of biomarkers for stem cells (Figure 6A) in the crypts. Studies with cultured crypt organoids confirmed the lack of cell proliferation and organoid growth upon induction of Bccip deletion in vitro (Figure 6, B-D). Furthermore, the Bccip deletion-induced intestinal crypt collapse was accompanied by transcriptional down-regulation genes involved in mitotic cell division and a stimulation of the genes not only in apoptotic cell death but also in response to microbiome and immune response. Although there was a robust induction of apoptosis (Figures 3B and 5C) upon Bccip deletion, inhibition of apoptosis did not rescue the growth arrest of organoids (data not shown). Thus, in the context of Bccip deletion- induced collapse of intestinal crypts, apoptosis is likely a terminal consequence of the failed cell cycle progression and generation of spontaneous DNA damage in the proliferative cells.

It is well known that regeneration of the intestinal epithelium requires coordinated signaling networks that instruct the stem and progenitor cells to proliferate and differentiate, such as the Wnt/ $\beta$-catenin and the Notchless signaling networks. ${ }^{3,26,28,29,31}$ Our data suggest that the role of $B C C I P$ in supporting intestinal renewal may be distinct from the previously identified pathways as Wnt3a failed to rescue or delay the growth arrest caused by Bccip deletion. The Villin-CreERT-mediated Notchless deletion induced intestinal disruption, but the mice with Notchless deletion survived, and co-deletion of Trp53 allowed recovery of the intestinal stem cell cycle and differentiation. ${ }^{26}$ In contrast, Bccip homozygous mice died within 5 days after tamoxifen injections in both Rosa-CreERT2 and Villin-CreERT mouse models, and co-deletion of Trp53 with Bccip failed to rescue the lethality of the mice. This outcome suggests that the mechanisms responsible for loss of intestinal crypt cells and the ultimate lethality of the Bccip null mice are distinct from either the accumulation of DNA damage in these cells leading to Trp53-dependent apoptosis, or from the induction of the Trp53-dependent defects in mouse intestinal/stem progenitor cells, previously observed in mice after deletion of Notchless, a regulator of ribosome biogenesis. ${ }^{26}$

Although our data suggest that Bccip is a critical gene to maintain the integrity and homeostasis of intestinal epithelium, and a rapid halt of mitotic cell division caused by Bccip deletion may be a direct cause of the crypt collapse, there is little information in the literature on whether Bccip dysregulation occurrs in human diseases involving crypt regeneration. This is likely due to the critical need for Bccip in intestinal development. A recent study reported that 
A

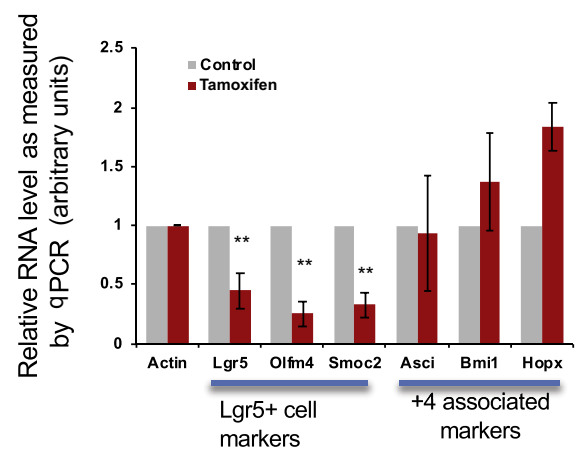

B

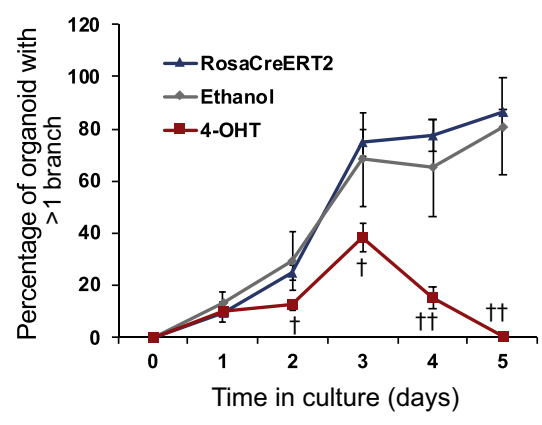

C

Days after induced Bccip deletion in organoid culture

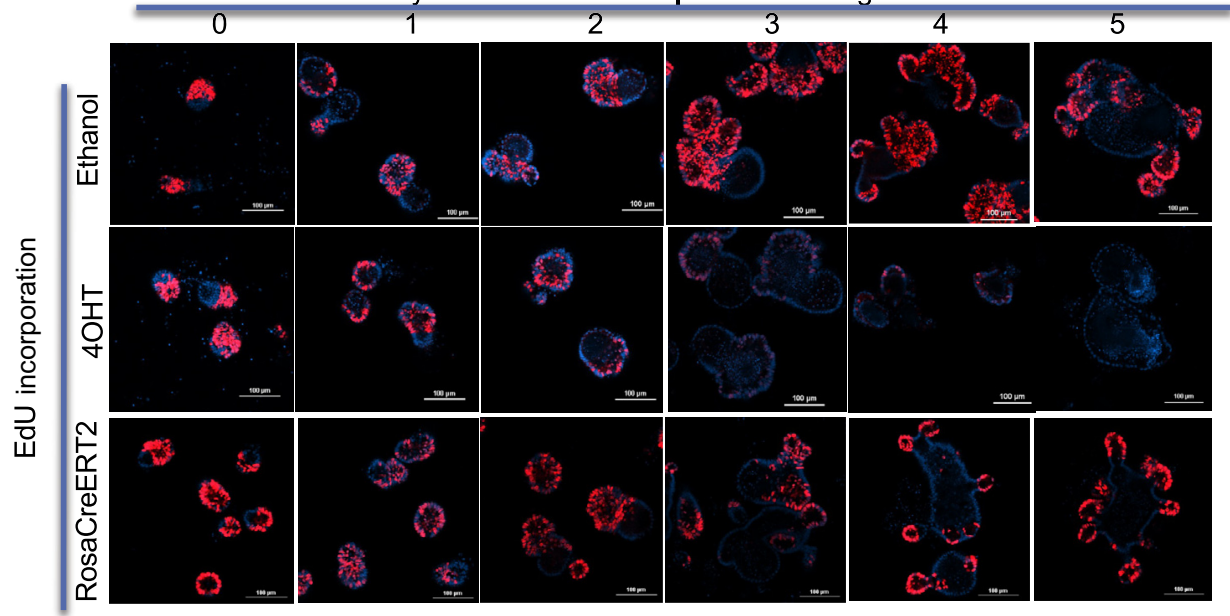

D
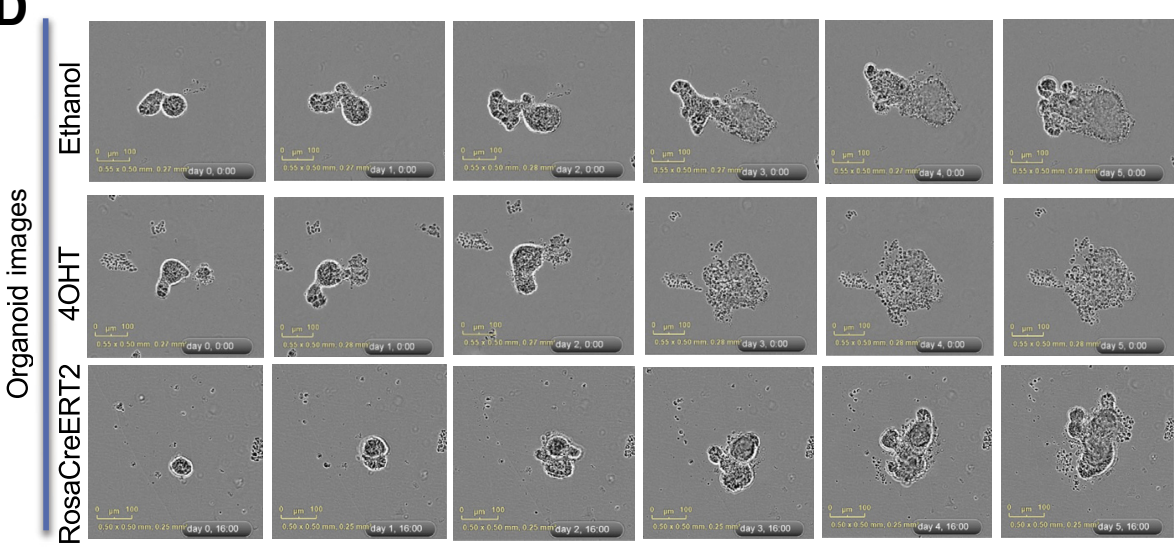

Figure 6 Induced Bccip knockout impairs organoid growth in vitro. A: Relative RNA levels of intestinal stem cell markers. Real-time RT-PCR was performed to measure the relative RNA level of several selected stem cell markers in the isolated intestinal crypts of the Bccip $p^{f / f}$; Rosa-CreERT2 and $B c c i p^{w t / w t}$;Rosa-CreERT2 mice. The crypts were isolated two days after the mice were treated with tamoxifen for 3 days. Shown are average and SD of four pairs of mouse crypts. Gray bars represent control mice, and red bars represent Bccip deletion mice. B: Percentage of organoids that have at least two branching buds. Data were based on counting of the Z-Stack images with 5-ethynyl-2'-deoxyuridine (EdU) as shown in C. C: Representative confocal microscope images illustrating the proliferative cells in the culture organoids. The organoids were labeled with EdU for 6 hours, fixed, and stained for EdU (red) and DNA (blue) at various times, as indicated. Top row: organoid isolated from Bccip ${ }^{w t / w t} ;$ Rosa-CreERT2 mouse treated with 4-hydroxytamoxifen $(40 \mathrm{HT})$ as a control; middle row: Bccip/f; ;osa-CreERT2 organoids treated with ethanol as another control; bottom row: $B c c i p^{f / f}$;Rosa-CreERT2 organoids treated with $40 \mathrm{HT}$ (Bccip deletion). Representative three-dimensional image visualizations can be found in Supplemental Videos S1-S3. D: Representative microscope images of cultured organoids at various times after in vitro treatments with ethanol (control, middle row), 40HT-treated Bccip ${ }^{w t / w t} ;$ Rosa-CreERT2 (as another control, top row), and 40HT-treated Bccip ${ }^{f / f} ;$ Rosa-CreERT2 (Bccip deletion, bottom row). Representative time-lapse videos can be found in Supplemental Videos S4, S5, and S6. ${ }^{* *} P<0.01$ versus control; ${ }^{\dagger} P<0.05,{ }^{\dagger \dagger} P<0.0140 \mathrm{HT}$-treated Bccip ${ }^{f / f} ;$ Rosa-CreERT2 versus Bccip ${ }^{w t / w t} ;$ Rosa-CreERT2. Scale bars $=100 \mu \mathrm{m}$. 


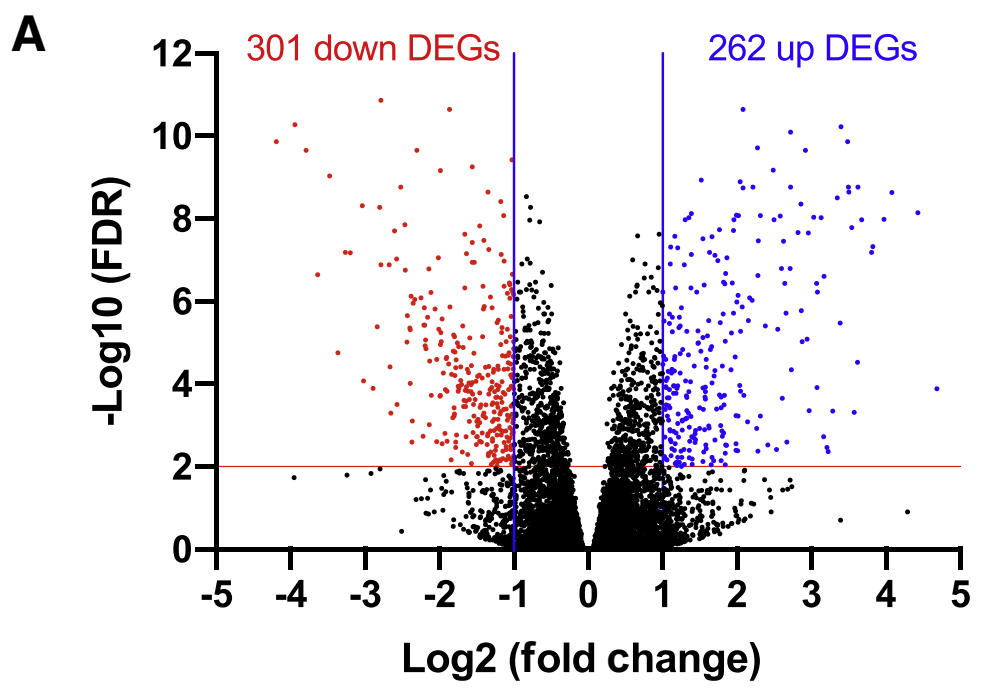

B

\section{Down DEGs}

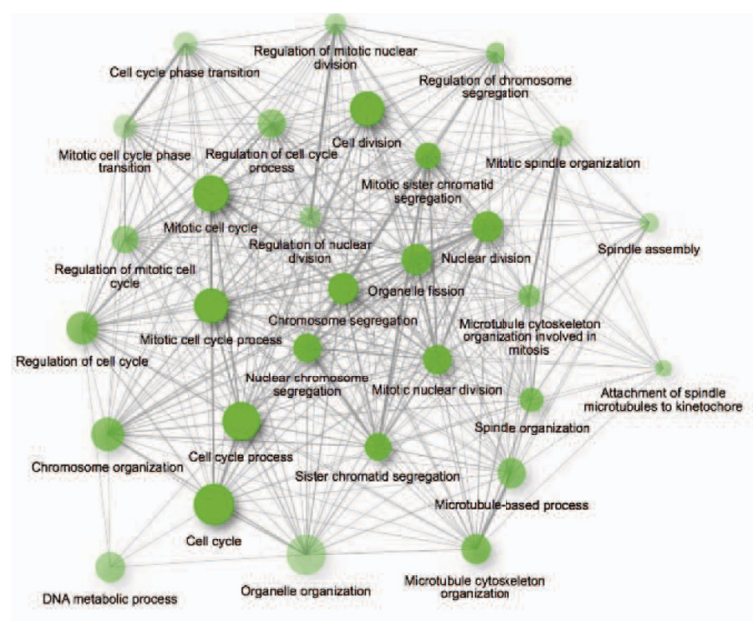

C

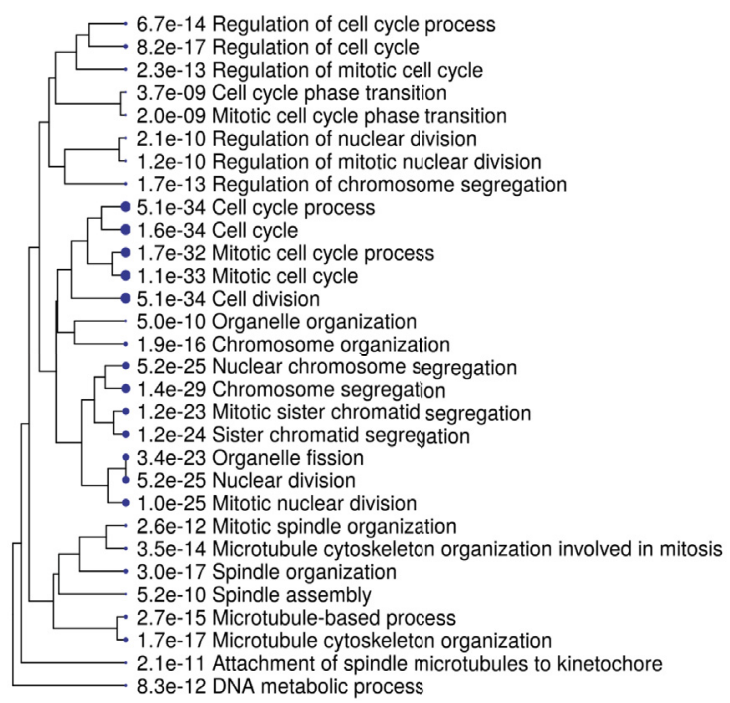

D

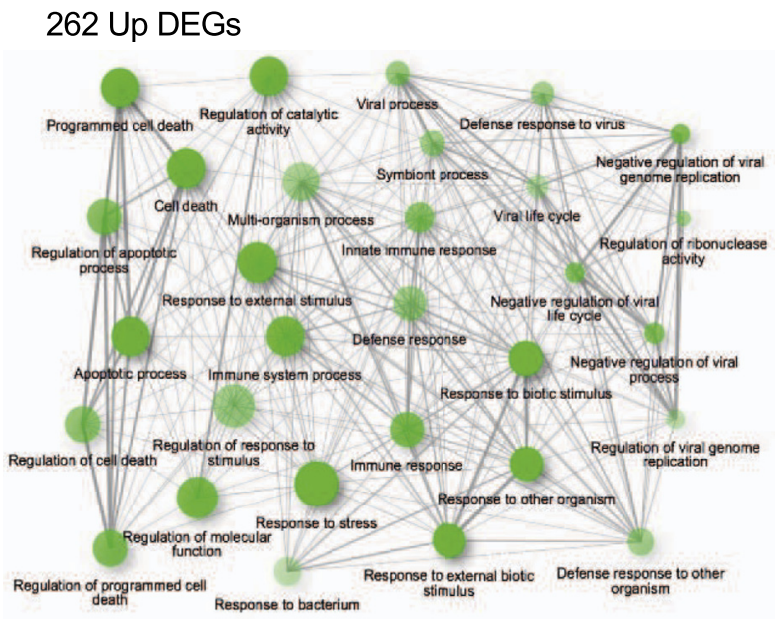

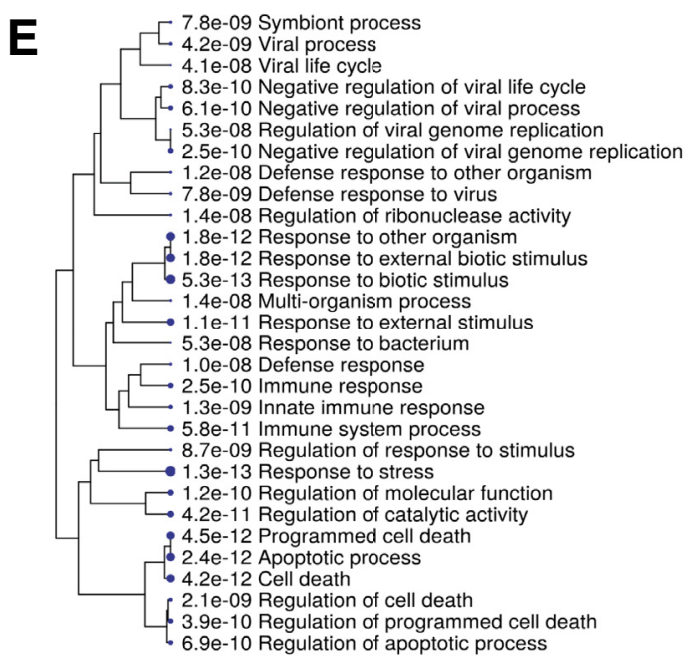

Figure 7 Bccip deletion alters the expression of genes associated with mitotic division, apoptosis, and stress response to the microbiome. A: Volcano plot showing the scatter of up- or down-regulated genes after Bccip deletion. Highlighted are the genes with a false discovery rate (FDR) $<0.01$ and at least twofold changes. A complete list of the differentially expressed genes (DEGs) is shown in Supplemental Table S2. B and C: Gene Ontology network and the enrichment of the up-regulated genes. $\mathbf{D}$ and $\mathbf{E}$ : Gene Ontology network and enrichment of the down-regulated genes. 
mosaic and heterozygous Bccip loss can cause chronic inflammation in the liver. ${ }^{18}$ It would be interesting to investigate whether a partial Bccip deficiency contributes to inflammatory diseases in the intestinal tissues.

Previous studies with shuttle vector-based knockdown of $B C C I P$ have shown that mild down-regulation $(<50 \%)$ of $B C C I P$ is sufficient to cause homologous recombination defects, genomic instability, and cell cycle abnormalities. $^{10,14-16}$ A conditional Bccip knockdown of $60 \%$ to $80 \%$ in mice is sufficient to cause embryonic lethality and severe neuro-degeneration, ${ }^{12,22}$ and can trigger the initiation of medulloblastoma and benign breast lesions. ${ }^{19,32}$ Because a homozygous Bccip deletion resulted in a complete loss of cell proliferation of the intestinal crypts, it is not surprising that $B C C I P$ null mutation has been rarely reported in cancers. However, BCCIP down-regulation has been observed in colorectal and other cancers. ${ }^{33}$ Although the heterozygous mice were viable (Table 1), we did not observe clear abnormalities in their intestinal tissues. It would be interesting to determine whether a partial loss of $B C C I P$ function or hypomorphic $B C C I P$ mutations confers a risk of colorectal cancer development upon genotoxic damage.

In conclusion, our studies suggest Bccip as a unique factor for the proliferation of intestinal progenitors and the renewal of intestinal epithelium.

\section{Author Contributions}

Z.S. conceptualized the study; Z.S. acquired funding; H.L., C.Y., and J.L. performed the investigation; H.L., C.Y., J.L., and S.D. developed methodology; A.B.R., M.V., S.D., and Z.S. acquired resources; Z.S. supervised the study; H.L. and Z.S. performed visualization; H.L. and Z.S. wrote the manuscript; A.B.R, M.V., S.D., and Z.S. wrote and edited the manuscript.

\section{Supplemental Data}

Supplemental material for this article can be found at http://doi.org/10.1016/j.ajpath.2020.09.009.

\section{References}

1. Mayhew TM, Myklebust R, Whybrow A, Jenkins R: Epithelial integrity, cell death and cell loss in mammalian small intestine. Histol Histopathol 1999, 14:257-267

2. Petkau K, Parsons BD, Duggal A, Foley E: A deregulated intestinal cell cycle program disrupts tissue homeostasis without affecting longevity in Drosophila. J Biol Chem 2014, 289:28719-28729

3. Qiu W, Wang X, Buchanan M, He K, Sharma R, Zhang L, Wang Q, Yu J: ADAR1 is essential for intestinal homeostasis and stem cell maintenance. Cell Death Dis 2013, 4:e599

4. Clevers H: The intestinal crypt, a prototype stem cell compartment. Cell 2013, 154:274-284
5. Perekatt AO, Valdez MJ, Davila M, Hoffman A, Bonder EM, Gao N, Verzi MP: YY1 is indispensable for Lgr5+ intestinal stem cell renewal. Proc Natl Acad Sci U S A 2014, 111:7695-7700

6. Marshman E, Booth C, Potten CS: The intestinal epithelial stem cell. Bioessays 2002, 24:91-98

7. Liu J, Yuan Y, Huan J, Shen Z: Inhibition of breast and brain cancer cell growth by BCCIPalpha, an evolutionarily conserved nuclear protein that interacts with BRCA2. Oncogene 2001, 20:336-345

8. Ono T, Kitaura H, Ugai H, Murata T, Yokoyama KK, IguchiAriga SM, Ariga H: TOK-1, a novel p21Cip1-binding protein that cooperatively enhances p21-dependent inhibitory activity toward CDK2 kinase. J Biol Chem 2000, 275:31145-31154

9. Meng X, Liu J, Shen Z: Inhibition of G1 to S cell cycle progression by BCCIP beta. Cell Cycle 2004, 3:343-348

10. Lu H, Yue J, Meng X, Nickoloff JA, Shen Z: BCCIP regulates homologous recombination by distinct domains and suppresses spontaneous DNA damage. Nucleic Acids Res 2007, 35:7160-7170

11. Huhn SC, Liu J, Ye C, Lu H, Jiang X, Feng X, Ganesan S, White E, Shen Z: Regulation of spindle integrity and mitotic fidelity by BCCIP. Oncogene 2017, 36:4750-4766

12. Lu H, Huang YY, Mehrotra S, Droz-Rosario R, Liu J, Bhaumik M, White E, Shen Z: Essential roles of BCCIP in mouse embryonic development and structural stability of chromosomes. PLoS Genet 2011, 7:e1002291

13. Wray J, Liu J, Nickoloff JA, Shen Z: Distinct RAD51 associations with RAD52 and BCCIP in response to DNA damage and replication stress. Cancer Res 2008, 68:2699-2707

14. Meng X, Yue J, Liu Z, Shen Z: Abrogation of the transactivation activity of p53 by BCCIP down-regulation. J Biol Chem 2007, 282: $1570-1576$

15. Meng X, Fan J, Shen Z: Roles of BCCIP in chromosome stability and cytokinesis. Oncogene 2007, 26:6253-6260

16. Lu H, Guo X, Meng X, Liu J, Allen C, Wray J, Nickoloff JA, Shen Z: The BRCA2-interacting protein BCCIP functions in RAD51 and BRCA2 focus formation and homologous recombinational repair. Mol Cell Biol 2005, 25:1949-1957

17. Meng X, Lu H, Shen Z: BCCIP functions through p53 to regulate the expression of p21Waf1/Cip1. Cell Cycle 2004, 3: 1457-1462

18. Lu H, Ye C, Feng X, Liu J, Bhaumik M, Xia B, Liu C, Shen Z: Spontaneous development of hepatocellular carcinoma and B-cell lymphoma in mosaic and heterozygous Brca2 and Cdkn1a interacting protein knockout mice. Am J Pathol 2020, 190: 1175-1187

19. Huang YY, Dai L, Gaines D, Droz-Rosario R, Lu H, Liu J, Shen Z: BCCIP suppresses tumor initiation but is required for tumor progression. Cancer Res 2013, 73:7122-7133

20. Rewari A, Lu H, Parikh R, Yang Q, Shen Z, Haffty BG: BCCIP as a prognostic marker for radiotherapy of laryngeal cancer. Radiother Oncol 2009, 90:183-188

21. Granier CJ, Wang W, Tsang T, Steward R, Sabaawy HE, Bhaumik M, Rabson AB: Conditional inactivation of PDCD2 induces p53 activation and cell cycle arrest. Biol Open 2014, 3:821-831

22. Huang YY, Lu H, Liu S, Droz-Rosario R, Shen Z: Requirement of mouse BCCIP for neural development and progenitor proliferation. PLoS One 2012, 7:e30638

23. Patro R, Duggal G, Love MI, Irizarry RA, Kingsford C: Salmon provides fast and bias-aware quantification of transcript expression. Nat Methods 2017, 14:417-419

24. Robinson MD, McCarthy DJ, Smyth GK: edgeR: a Bioconductor package for differential expression analysis of digital gene expression data. Bioinformatics 2010, 26:139-140

25. Kelso AA, Goodson SD, Watts LE, Ledford LL, Waldvogel SM, Diehl JN, Shah SB, Say AF, White JD, Sehorn MG: The [beta]isoform of BCCIP promotes ADP release from the RAD51 presynaptic filament and enhances homologous DNA pairing. Nucleic Acids Res 2017, 45:711-725 
26. Stedman A, Beck-Cormier S, Le Bouteiller M, Raveux A, VandormaelPournin S, Coqueran S, Lejour V, Jarzebowski L, Toledo F, Robine S, Cohen-Tannoudji M: Ribosome biogenesis dysfunction leads to p53mediated apoptosis and goblet cell differentiation of mouse intestinal stem/progenitor cells. Cell Death Differ 2015, 22:1865-1876

27. Clevers H: Wnt/beta-catenin signaling in development and disease. Cell 2006, 127:469-480

28. Gregorieff A, Clevers $\mathrm{H}$ : Wnt signaling in the intestinal epithelium: from endoderm to cancer. Genes Dev 2005, 19:877-890

29. Fevr T, Robine S, Louvard D, Huelsken J: Wnt/beta-catenin is essential for intestinal homeostasis and maintenance of intestinal stem cells. Mol Cell Biol 2007, 27:7551-7559

30. Bourhis E, Tam C, Franke Y, Bazan JF, Ernst J, Hwang J, Costa M, Cochran AG, Hannoush RN: Reconstitution of a
frizzled8.Wnt3a.LRP6 signaling complex reveals multiple Wnt and Dkk1 binding sites on LRP6. J Biol Chem 2010, 285: 9172-9179

31. Schuijers J, Junker JP, Mokry M, Hatzis P, Koo BK, Sasselli V, van der Flier LG, Cuppen E, van Oudenaarden A, Clevers H: Ascl2 acts as an R-spondin/Wnt-responsive switch to control stemness in intestinal crypts. Cell Stem Cell 2015, 16:158-170

32. Droz-Rosario R, Lu H, Liu J, Liu NA, Ganesan S, Xia B, Haffty BG, Shen Z: Roles of BCCIP deficiency in mammary tumorigenesis. Breast Cancer Res 2017, 19:115

33. Liu X, Cao L, Ni J, Liu N, Zhao X, Wang Y, Zhu L, Wang L, Wang J, Yue Y, Cai Y, Jin J: Differential BCCIP gene expression in primary human ovarian cancer, renal cell carcinoma and colorectal cancer tissues. Int J Oncol 2013, 43:1925-1934 